\title{
Predicting Conversion to MS - The Role of a History Suggestive of Demyelination
}

\author{
Sarah A. Morrow, J. Alexander Fraser, David Nicolle, Marcelo Kremenchutzky
}

\begin{abstract}
Background: The ability to predict conversion to multiple sclerosis (MS) accurately when assessing a patient with a clinically isolated syndrome (CIS) is of paramount importance. Magnetic resonance imaging (MRI) is the best paraclinical tool currently available; however the significance of a history of an event suggestive of demyelination prior to CIS presentation has not been evaluated. Methods: A retrospective chart review of all optic neuritis cases presenting as CIS to a single neuro-ophthalmologist in London, Ontario between 1990 to 1998 was performed. Data were collected regarding demographics, past medical history, history of present illness, and family history. Conversion to MS was determined by the McDonald criteria after ten years of follow-up. Bayesian statistics and logistic regression were used to determine the best predictors of conversion to MS from CIS. Results: One hundred and sixteen optic neuritis subjects were included in the analysis. After ten years, $42.2 \%$ had converted to MS. The best predictor of future conversion remained at least one brain lesion, disseminated in space, on MRI (sensitivity 0.90 , specificity 0.75 ). However, if the subject additionally had a history suggestive of a demyelinating event in the past that had not been confirmed clinically, the specificity increased to 0.96 . These two traits taken together had an odds ratio of 27.8 for conversion to MS in the next ten years $(\mathrm{p}<0.001)$. Conclusions: A history of an event suggestive of demyelination prior to presenting with optic neuritis as CIS increases the ability of the clinician to predict conversion to MS in the next ten years.
\end{abstract}

RÉSUMÉ: Le rôle d'une histoire antérieure suggestive d'une démyélinisation dans la prédiction de la conversion à la SP. Contexte : La capacité de prédire avec exactitude la conversion à la sclérose en plaques (SP) lorsqu'on évalue un patient qui présente un syndrome clinique isolé (SCI) est extrêmement importante. L'IRM est le meilleur outil paraclinique disponible actuellement. Cependant, la signification d'une histoire d'événement antérieur au SCI suggestif d'une démyélinisation n'a jamais été évaluée. Méthodes : Nous avons effectué une revue rétrospective des dossiers de tous les cas de névrite optique comme SCI qui ont été examinés par le même neuro-ophtalmologiste à London, en Ontario, entre 1990 et 1998. Les données démographiques, l'histoire médicale antérieure, l'histoire de la maladie actuelle et l'histoire familiale ont été colligées. La conversion à la SP a été déterminée selon les critères de McDonald après un suivi de dix ans. Nous avons utilisé les statistiques bayésiennes et la régression logistique pour déterminer ce qui prédisait le mieux la conversion d'un SCI à la SP. Résultats : Cent seize patients atteints de névrite optique ont été inclus dans l'étude. Après dix ans, 42,2\% étaient atteints de SP. Ce qui prédisait le mieux la conversion demeurait la présence à l'IRM d'au moins une lésion cérébrale disséminée dans l'espace (sensibilité 0,90 , spécificité 0,75 ). Cependant, si le sujet avait en plus une histoire suggestive d'un événement démyélinisant dans le passé, qui n'avait pas été confirmé au point de vue clinique, la spécificité augmentait à 0,96 . Quand ces deux facteurs étaient considérés simultanément, le rapport de cotes était 27,8 pour la conversion à la SP au cours des 10 années subséquentes $(\mathrm{p}<0,001)$. Conclusions : Une histoire antérieure d'un événement suggestif d'un épisode de démyélinisation chez un patient qui consulte pour une névrite optique comme SCI est un indice qui aide le clinicien à prédire une conversion à la SP au cours des dix prochaines années.

Can. J. Neurol. Sci. 2010; 37: 488-491

The ability to predict conversion to multiple sclerosis (MS) correctly when assessing a patient with optic neuritis $(\mathrm{ON})$ as a first demyelinating episode continues to be an important concern in clinical practice. This issue has become even more pressing with the approval of disease modifying treatment for clinically isolated syndromes (CIS), including optic neuritis. The groundbreaking Optic Neuritis Treatment Trial (ONTT), with its 10 and 15 year follow-up data published as the Longitudinal Optic Neuritis Study, demonstrated the importance of magnetic resonance imaging (MRI) and demographic characteristics in predicting the risk of conversion to MS following an episode of $\mathrm{ON}^{1-3}$, and has been supported by other studies ${ }^{4-6}$. Thus MRI has become the tool most often used to predict the risk of conversion to MS from CIS over ten years 5 . Yet, MRI characteristics still do not have $100 \%$ specificity or sensitivity in identifying those who will develop MS, and other paraclinical elements are needed to further refine the prognosis. Commonly, CIS subjects present with a history of an event in the past that is suggestive of

From the State University of New York at Buffalo (SAM), The Jacobs Neurological Institute, Buffalo, New York, U.S.A; Department of Ophthalmology (JAF, DN), Department of Clinical Neurological Sciences (JAF, MK), University of Western Ontario, London, Ontario, Canada.

Received December 22, 2009. Final Revisions Submitted February 2, 2010. Correspondence to: Sarah A. Morrow, The Jacobs Neurological Institute, Buffalo General Hospital, 100 High Street, Buffalo, New York, 14215, U.S.A. 
demyelination. The revised McDonald criteria in 2005 acknowledge that the presence of such an event on history should trigger a search for objective findings, yet the panel did not endorse using subjective historical reports suggestive of demyelination, even if objective paraclinical findings are in place, to make a definitive diagnosis of $\mathrm{MS}^{7}$. Consequently, if this event cannot be confirmed, either on the current physical examination or with documented evidence of neurological signs at the time of the past event, it does not fit the McDonald revised criteria for dissemination in space and time ${ }^{7}$. We endeavored to investigate the predictive value of a history of an event suggestive of demyelination, unconfirmed with objective deficits or documentation of these symptoms, in the prediction of conversion to MS over a ten year follow-up period, in addition to MRI findings after an episode of ON.

\section{Methods}

\section{Case Identification and Data Collection}

Only one practicing neuro-ophthalmologist was located in London, Ontario prior to 2007 for the catchment area of southwestern Ontario. Standard practice for all ON cases included an MRI study and referral to the London MS Clinic (University of Western Ontario, London, Canada) which provides specialized tertiary care for MS patients from its referral area of Southwestern Ontario.

A retrospective chart review of the neuro-ophthalmology charts was performed to identify subjects presenting with $\mathrm{ON}$ as a first demyelinating event between 1990 and 1998. Subjects with an established prior diagnosis of CIS or MS, or a confirmed demyelinating event in the past were excluded. Demographics, history of present illness, past medical history, family history, and physical exam findings pertaining to $\mathrm{ON}$ of the subject were collected at initial presentation. A history of an event suggestive of demyelination in the past was part of the standard history performed by the neuro-ophthalmologist. Such an event was defined by a symptom typical of demyelination, such as unilateral decreased vision, diplopia, unilateral or bilateral limb numbness/clumsiness or Lhermitte's symptom, present for at least 24 hours but had not been assessed by a physician at the time. Conversion to MS was determined, retrospectively, according to McDonald criteria for dissemination in time or space. Information on conversion to MS was based on chart reviews from the MS and neuro-ophthalmology clinic as well as MRI reports and the hospital chart. This study was approved by the University of Western Ontario Institutional Review Board.

\section{Statistical Analysis}

Bayesian statistics predicting conversion to MS were calculated in the traditional way: sensitivity = true positives/(true positive + false negatives), specificity $=$ true negatives/(true negatives + false positives), positive predictive value $=$ true positives/(true positives + false positives) and negative predictive value $=$ true negatives $/($ true negatives + false negatives). Forward stepwise logistic regression models, with $\mathrm{p}$ to enter 0.05 and to exit 0.10 , were used to determine which characteristics - including age at presentation, family history of MS, gender, and a history suggestive of a demyelinating event in the past - best predicted conversion to MS, with and without MRI at presentation included as a variable.

\section{RESULTS}

\section{Demographics and History of Presentation}

A total of 139 patients with a first presentation of ON were identified, of whom 15 did not have an initial MRI and eight were lost to follow-up; thus a full-case wise analysis was performed with the 116 subjects in the cohort. The mean age at presentation was $36.4 \pm 10.2$ years, $75.0 \%$ were female, $7.7 \%$ reported a family history of MS (3.4\% in a first degree relative) and $24.1 \%$ had a history of symptoms suggestive of demyelination that had not been clinically confirmed at the time of the symptoms. More than half (68 subjects, 58.6\%) were examined within two weeks of initial symptom onset and 92 $(79.3 \%)$ continued to be symptomatic at that time. Seven subjects $(6 \%)$ presented with bilateral $\mathrm{ON}$, but otherwise the sample was equally divided between involvement of the left (55, $47.4 \%)$ and right $(53,45.7 \%)$ eyes. Initial MRI findings were as follows: 31 (26.7\%) normal, 24 (20.7\%) with ON only, 4 (3.4\%) with one typical demyelination lesion other than in the affected optic nerve, $30(25.9 \%)$ with one or more other lesion typical of demyelination but not meeting McDonald's criteria for dissemination in space and $27(23.3 \%)$ met McDonald's criteria for dissemination in space. Over ten years, 49 subjects (42.2\%) converted to MS based on a second clinical event (35 subjects, $71.4 \%$ ), laboratory support (3 subjects, $6.1 \%$ ) or based on dissemination in space and time on a future MRI $(11,22.5 \%)$.

\section{Bayesian Analysis}

Results of statistical analysis are shown in Table 1. Findings of dissemination in space on the initial MRI had a sensitivity of 0.43 , but a specificity of 0.91 for correct prediction of conversion to MS in the next ten years. However, an MRI at presentation with at least one lesion typical of demyelination other than $\mathrm{ON}$ (i.e. disseminated in space from the clinical event), correctly predicted the conversion to MS with a sensitivity of 0.90 and a

\section{Table 1: Bayesian statistics for the impact of MRI and a history suggestive of demyelinating events on the ability to predict conversion to MS}

\begin{tabular}{|c|c|c|c|c|}
\hline Variable & Sensitivity & Specificity & PPV & NPV \\
\hline $\begin{array}{l}\text { MRI } \\
\text { - McDonald criteria met for DS } \\
-1 \text { or more } \mathrm{T} 2 \text { lesions typical of } \\
\text { demyelination* }\end{array}$ & $\begin{array}{l}0.43 \\
0.90\end{array}$ & $\begin{array}{l}0.91 \\
0.75\end{array}$ & $\begin{array}{l}0.78 \\
0.90\end{array}$ & $\begin{array}{l}0.69 \\
0.91\end{array}$ \\
\hline $\begin{array}{l}\text { History suggestive of } \\
\text { demyelination }\end{array}$ & 0.33 & 0.82 & 0.57 & 0.63 \\
\hline $\begin{array}{l}\text { History suggestive of } \\
\text { demyelination AND on MRI } \\
\text { - McDonald DS criteria } \\
\text { - } 1 \text { or more T2 lesions typical of } \\
\text { demyelination* }\end{array}$ & $\begin{array}{l}0.12 \\
0.31\end{array}$ & $\begin{array}{l}0.97 \\
0.96\end{array}$ & $\begin{array}{l}0.75 \\
0.81\end{array}$ & $\begin{array}{l}0.60 \\
0.64\end{array}$ \\
\hline
\end{tabular}

* but not meeting McDonald's criteria for dissemination in space, MRI: Magnetic Resonance Imaging, DS: dissemination in space, PPV: positive predictive value, NPV: negative predictive value, MS: multiple sclerosis 
specificity of 0.75 , with a positive and negative predictive value of 0.90 and 0.91 respectively. In contrast, using a normal MRI to predict ON cases that would remain CIS had a high false negative rate (sensitivity 0.42) with few false positives (specificity 0.94), but if the MRI was either normal or had ON only, the accuracy was excellent (sensitivity 0.91, specificity 0.90). Similarly, in those who reported a history of a past event suggestive of a demyelinating event, the false negative rate was high (sensitivity 0.33 ) but with fewer false positives (specificity $0.84)$.

If the MRI at presentation fit McDonald's criteria for dissemination in space and the subject reported a history of past events suggestive of demyelination, few false positives were identified (specificity 0.97 ) although the false negative rate was high with a sensitivity of 0.12 . If the MRI at presentation had at least one lesion suggestive of MS and the subject reported a history of past events suggestive of demyelination, the specificity continued to be high (0.96) with fewer false negatives cases (sensitivity 0.31 ).

\section{Regression Analysis}

Results of logistic regression are shown in Table 2. Logistic regression demonstrated that MRI findings continue to be the strongest predictor of conversion to MS $(\mathrm{p}<0.001)$ with an odds ratio of 27.5. With MRI removed, the next most significant predictor of conversion to MS was a history of an episode suggestive of demyelination $(\mathrm{p}=0.049)$ with an odds ratio of 2.4. If the subject had at least one other lesion on MRI suggestive of dissemination in space, but not meeting McDonald's criteria with or without a history of a possible previous demyelination event, the odds ratio of converting to MS in the next ten years was 27.8 $(\mathrm{p}<0.001)$. The MRI at presentation and a history suggestive of demyelination together accounted for $50.2 \%$ of the variance in the model.

\section{Discussion}

The correct identification of CIS subjects who will convert to MS continues to be an important yet not fully defined issue. Although other demyelinating lesions on MRI are a strong predictor of the future conversion to MS, MRI alone it is not sufficient. No single test has been found that can accurately predict conversion to MS in CIS patients. This is the first study, to our knowledge, that examines the predictive power of a past history of an event suggestive of demyelination. The astute clinician would often consider this history as an important sign that this patient does indeed have MS, but could not, based on the McDonald criteria, make this diagnosis. Although statistically significant, a previous history of an event suggestive of demyelination alone is not an accurate predictor, as the $95 \% \mathrm{CI}$ of the odds ratio includes the null value (1.0), supporting its exclusion from the McDonald criteria. However, when coupled with an MRI that is suggestive of demyelination in space, a history of a potential event that fits criteria for dissemination in time and space decreases the number of false positives while maintaining a high positive predictive value of 0.81 , suggesting that few ON patients presenting with these two findings will not convert to MS over ten years. As future revisions are made to diagnostic criteria, in light of new MRI techniques and better
Table 2: Logistic regression results for the ability to predict conversion to MS

\begin{tabular}{l|l|l|l}
\hline Variable & Odds Ratio & $95 \%$ CI & P value \\
\hline MRI at presentation & 27.5 & $9.3,81.2$ & $<0.001$ \\
\hline History suggestive of demyelination & 2.4 & $1.0,5.8$ & 0.049 \\
\hline MRI and positive history & 27.8 & $9.3,83.3$ & $<0.001$ \\
\hline
\end{tabular}

MRI: McDonald's criteria; MS: Multiple Sclerosis, CI: confidence interval

understanding of the pathophysiology of this disease, consideration of a history as described here may warrant inclusion. The ability to prognosticate the future risk of MS in CIS patients has become more important in light of recent research. Studies involving interferon- $\beta$ and glatiramer acetate treatment after a CIS have consistently shown a delay in the time to next relapse compared to placebo ${ }^{8-11}$. Additionally, early treatment with interferon $\beta$-1a has shown to slow the progression of atrophy, which has been found to be associated with cognitive impairment ${ }^{12}$. Yet, these medications are costly and all require self-injection, either subcutaneously or intramuscularly, and have adverse events ranging from mild skin changes to fulminant liver failure ${ }^{13-15}$. Thus, advising an individual patient regarding the risk/benefit ratio of starting treatment is an important part of our role as clinicians, as some CIS patients will never convert to MS and will suffer significant side-effects without any clear indication of benefit if treatment is initiated.

Magnetic resonance imaging has become the most important paraclinical tool to assist clinicians in forming a prognosis regarding a CIS patients' future risk of MS. The ONTT ten year follow-up data showed that $38 \%$ of ON subjects converted to MS over ten years, increasing to $56 \%$ if there was one or more T2 lesion on initial MRI ${ }^{2}$. In our study, $42.2 \%$ converted to MS over ten years; this rate is slightly higher than the $38 \%$ found in the ONTT ten year data. However, the ONTT used Poser's criteria for the diagnosis of MS, requiring a second clinical event, while we used the revised McDonald criteria, which incorporates MRI and cerebrospinal fluid oligoclonal bands (OCB) to fulfill the requirement of dissemination in space and time, which may account for the difference in our findings.

In a study of all CIS presentations (not restricted to ON), O'Riordan et al found $33 \%$ of patients with one typical demyelinating T2 lesion on MRI converted to MS within ten years, a figure which increased to $87 \%$ if the MRI had one or more typical demyelinating T2 lesion ${ }^{5}$. These findings have been confirmed by other studies ${ }^{4,6}$. Barkhof et al found the accuracy of predicting the conversion to MS based on MRI was optimal at a minimum of $9 \mathrm{~T} 2$ lesions $^{16}$, which was the basis for the MRI component of the McDonald diagnostic criteria. Clearly, MRI is an invaluable tool in the prediction of future risk of MS, but still leads to some inaccuracy.

Other studies have focused on the addition of OCB testing, in combination with MRI, to expand the definition of dissemination in space and time and to increase the accuracy of prediction of conversion to MS after a CIS. Oligoclonal bands have been 
found to have a relatively high sensitivity (94.4\%) and negative predictive value $(88.9 \%)$ for $\mathrm{MS}^{17}$. Tintore et al found that the presence of OCB increased the risk of conversion to MS twofold, independent of the MRI findings and that OCB were most useful in those CIS subjects who had a normal MRI or did not meet the McDonald criteria for dissemination in space ${ }^{18}$. However, the quality of CSF analysis for OCB is not uniform, affecting the accuracy and thus reliability of the results obtained ${ }^{19,20}$. Additionally, OCB analysis requires an invasive procedure, lumbar puncture, which is not always acceptable to patients.

Demographics and CIS characteristics have also been studied as additional predictors to improve the accuracy of MS diagnosis. A younger age at onset of CIS and ON as the first CIS, as opposed to another demyelinating event, have been found to increase the risk of conversion to $\mathrm{MS}^{21}$. Furthermore, a non-white race, younger age, and monofocal presentation were found to increase the risk of a second demyelinating event within one year of CIS presentation ${ }^{22}$. No previous studies have investigated the use of history-taking for events suggestive of previous demyelinating events, a standard part of a neurological evaluation, in the prognosis of CIS conversion to MS.

There are several weaknesses in our study. There may have been a selection bias in terms of which ON cases were managed by general ophthalmologists versus those referred to a neuroophthalmologist. Furthermore, in our study, there were 15 subjects who refused an MRI and thus could not be included in the analysis. Otherwise, however, there were a low number of subjects lost to follow-up (5.8\%). Additionally, since this is a retrospective clinical cohort, OCB was not uniformly tested in all subjects. Finally, the ability to identify a past event suggestive of demyelination is dependent on the history-taking skills of the clinician which may differ from that of our neuroophthalmologist, affecting the accuracy of its predictive value.

\section{Conclusions}

Overall, our study indicates that a thorough clinical history, with an emphasis on past events suggestive of demyelination, may increase the yield of MRI in predicting a conversion to MS and may help clinicians further advise individual patients regarding their risk of developing MS.

\section{REFERENCES}

1. Optic Neuritis Treatment Group. Multiple sclerosis risk after optic neuritis: final optic neuritis treatment trial follow-up. Arch Neurol. 2008;65:727-32.

2. Optic Neuritis Study Group. High- and low-risk profiles for the development of multiple sclerosis within 10 years after optic neuritis: experience of the optic neuritis treatment trial. Arch Ophthal. 2003;121:944-9.

3. Optic Neuritis Study Group. Neurologic impairment 10 years after optic neuritis. Arch Neurol. 2004;61:1386-9.

4. Morrissey SP, Miller DH, Kendall BE, Kingsley DP, Kelly MA, Francis DA, et al. The significance of brain magnetic resonance imaging abnormalities at presentation with clinically isolated syndromes suggestive of multiple sclerosis. A 5-year follow-up study. Brain, 1993;116(Pt 1):135-6.

5. O'Riordan JI, Thompson AJ, Kingsley DP, MacManus DG, Kendall $\mathrm{BE}$, Rudge $\mathrm{P}$, et al. The prognostic value of brain MRI in clinically isolated syndromes of the CNS. A 10-year follow-up. Brain. 1998;121(Pt 3):495-503

6. Brex PA, Ciccarelli O, O'Riordan JI, Sailer M, Thompson AJ, Miller $\mathrm{DH}$. A longitudinal study of abnormalities on MRI and disability from multiple sclerosis. N Engl J Med. 2002;346:158-64.
7. Polman CH, Reingold SC, Edan G, Filippi M, Hartung HP, Kappos L, et al. Diagnostic criteria for multiple sclerosis: 2005 revisions to the "McDonald Criteria". Ann Neurol. 2005;58: 840-6.

8. Champs Study Group. Interferon beta-1a for optic neuritis patients at high risk for multiple sclerosis. Am J Ophthal. 2001;132: 463-71.

9. Kappos L, Polman CH, Freedman MS, Edan G, Hartung HP, Miller $\mathrm{DH}$, et al. Treatment with interferon beta- $1 \mathrm{~b}$ delays conversion to clinically definite and McDonald MS in patients with clinically isolated syndromes. Neurology. 2006;67:1242-9.

10. Comi G, Filippi M, Barkhof F, Durelli L, Edan G, Fernandez O, et al. Effect of early interferon treatment on conversion to definite multiple sclerosis: a randomised study. Lancet. 2001;357: 1576-82.

11. Comi G, Martinelli V, Rodegher M, Moiola L, Bajenaru O, Carra A, et al. Effect of glatiramer acetate on conversion to clinically definite multiple sclerosis in patients with clinically isolated syndrome (PreCISe study): a randomised, double-blind, placebocontrolled trial. Lancet. 2009;374(9700):1503-11.

12. Rudick RA, Fisher E, Lee JC, Duda JT, Simon J. Brain atrophy in relapsing multiple sclerosis: relationship to relapses, EDSS, and treatment with interferon beta-1a. Mult Scler. 2000;6:365-2.

13. Yoshida EM, Rasmussen SL, Steinbrecher UP, Erb SR, Scudamore $\mathrm{CH}$, Chung SW, et al. Fulminant liver failure during interferon beta treatment of multiple sclerosis. Neurology. 2001;56:1416.

14. Galetta SL, Markowitz C. US FDA-approved disease-modifying treatments for multiple sclerosis: review of adverse effect profiles. CNS Drugs. 2005;19:239-2.

15. Debouverie M, Moreau T, Lebrun C, Heinzlef O, Brudon F, Msihid J. A longitudinal observational study of a cohort of patients with relapsing-remitting multiple sclerosis treated with glatiramer acetate. Eur J Neurol. 2007;14:1266-74.

16. Barkhof F, Filippi M, Miller DH, Scheltens P, Campi A, Polman $\mathrm{CH}$, et al. Comparison of MRI criteria at first presentation to predict conversion to clinically definite mulltiple sclerosis. Brain. 1997; 120:2059-69.

17. Masjuan J, Alvarez-Cermeno JC, Garcia-Barragan N, DiazSanchez, Espino M, Sadaba MC, et al. Clinically isolated syndromes: a new oligoclonal band test accurately predicts conversion to MS. Neurology. 2006;66:576-8.

18. Tintore M, Rovira A, Rio J, Tur C, Pelayo R, Nos C, et al. Do oligoclonal bands add information to MRI in first attacks of multiple sclerosis? Neurology. 2008;70:1079-83.

19. McDonald WI, Compston A, Edan G, Goodkin D, Hartung H-P, Lublin FD, et al. Recommended diagnostic criteria for multiple sclerosis: guidelines from the international panel on the diagnosis of multiple sclerosis. Ann Neurol. 2001;50:121-7.

20. Reiber H, Thompson EJ, Grimsley G, Bernardi G, Adam P, Monterio de Almeida S, et al. Quality assurance for cerebrospinal fluid protein analysis: international consensus by an Internet-based group discussion. Clin Chem Lab Med. 2003; 41:331-7.

21. Soderstrom M, Ya-Ping J, Hillert J, Link H. Optic neuritis: prognosis for multiple sclerosis from MRI, CSF, and HLA findings. Neurology. 1998;50:708-14.

22. Mowry EM, Pesic M, Grimes B, Deen SR, Bacchetti P, Waubant E. Clinical predictors of early second event in patients with clinically isolated syndrome. J Neurol. 2009;256:1061-6. 